\title{
Effectiveness of Using Screencast Feedback on EFL Students' Writing and Perception
}

\author{
Amira Desouky Ali ${ }^{1}$ \\ ${ }^{1}$ Sadat Academy for Management Sciences, Egypt \\ Correspondence: Amira Desouky Ali, Sadat Academy for Management Sciences, Egypt. E-mail: \\ amora.desouky@gmail.com
}

Received: May 19, 2016 Accepted: June 24, 2016 Online Published: June 26, 2016

doi: 10.5539/elt.v9n8p106 URL: http://dx.doi.org/10.5539/elt.v9n8p106

\begin{abstract}
This mixed-methods research was carried out to investigate the effect of screencast video feedback on the writing of freshmen, studying academic writing course at a university in Egypt, and explore their perception towards receiving screencast feedback. Two classes of 63 students were chosen to participate in this study and were assigned into two groups; an experimental group (33 students) and a control one (30 students). While the control group received written comments, the experimental group received video feedback to the higher order concerns of writing (content, organization and structure) and written feedback to the lower order concerns (accuracy) of their writings. Two writing tests were administered to the two groups before and after the experiment. To investigate the perception towards screencast feedback, an online questionnaire was applied to the experimental group after the experiment. Results showed that the experimental group outperformed the control group in the higher order concerns of writing as well as the overall writing skill in the writing posttest. Findings also revealed that the majority of students in the experimental group perceived screencast feedback positively for being clear, personal, specific, supportive, multimodal, constructive, and engaging. However, they reported few challenges such as slow loading time and inability to download videos to their computers. The research concludes with implications for practitioners and researchers.
\end{abstract}

Keywords: screencast video feedback, EFL writing, perception, university students, mixed methodology

\section{Introduction}

Research on writing over the last two decades have replaced emphasis from summative feedback, focusing on the product, to formative feedback, focusing on the writing process and students' future practices (K. Hyland \& F. Hyland, 2006). Feedback is the backbone of formative assessment. Effective feedback is a two-way process and a continuous dialogue between teacher and students; therefore, it can improve learning process and outcomes. Price, Handley, Millar, and O'Donovan (2010) state that feedback falls "broadly into five, but not entirely delineated discrete, categories: correction, reinforcement, forensic diagnosis, benchmarking and longitudinal development (feed forward)" (p. 278). K. Hyland and F. Hyland (2006) point out the importance of feedback in the improvement of ESL students' writing and development of their motivation. They consider feedback as the key element to scaffold students' confidence and provide encouragement.

Gibbis and Simpson (2004) specify seven conditions for successful feedback: a) sufficient in terms of quality and quantity, b) relevant to students' performance rather than their personalities or characteristics, c) timely; addressing present and future issues related to students' learning, d) appropriate to the purpose of the assessment and its criteria, e) understandable; so that students understand what to do next, f) available to students, and g) useful and related to future work. Likewise, Nicol and Macfarlance-Dick's (2006) point out that effective feedback should clarify good performance, facilitate self-assessment and reflection in leaning, provide high quality information for students about their learning, encourage teacher-student and student-teacher discussion, develop positive attitudes and self-esteem, narrow the gap between present and future performance, and provide teachers with useful feedback to improve instruction.

However, Zhang and Kenny (2010) identify some challenges that might affect feedback negatively. Lack of clarity of feedback prevents students form interpreting it correctly or the same way as the teacher intends. Therefore, written feedback should be supported by examples. Misinterpretation might be due to the level of language difficulty of the teacher's comments especially in asynchronous online courses. In addition, computer 
anxiety might constitute an obstacle for e-feedback implementation. Unfamiliarity with peer feedback can make students perceive e-feedback as hard and time consuming. Adequate training on how to use given feedback and give feedback on peers' essays is pivotal in helping students to reflect on their own performance (Liu\& Sadler, 2003; Matsumura \& Hann, 2004). In addition, scholars point out that the focus of many students is the grades; therefore; little or no effort is done from the part students to revise their assignments; a factor that results in teachers' disappointment due to wasted time and effort (Higgins et al., 2001; Crisp, 2007, Bailey \& Garner, 2010, Orsmond \& Merry, 2011; cited in Henderson \& Phillips, 2015).

\subsection{Research Problem}

The researcher noticed that her undergraduate students failed to make meaningful revisions to their essays and focused more on accuracy revisions. Moreover, they were dissatisfied with their grades as they complained about not knowing where and why they lost marks even with the use of rubrics. They were also frustrated with the large number of explicit corrective comments on their written assignments. Likewise, discussions with EFL instructors and analysis of samples of students' graded essays revealed that the students don't receive adequate feedback on the content of their short-form writings and even if they did, the given written feedback focuses on the metalinguistic or linguistic features over content and organization.

\subsection{Research Aims}

The research was of two-fold. First, it aimed at investigating the effect of providing screencast video feedback on improving the quality of the students' essays. Second, it sought to explore the students' perception towards receiving video feedback on their essays.

\subsection{Significance of the Research}

The research will be significant to researchers, teachers, and curriculum designers. The research will contribute to the body of literature on using Web 2.0 technology in providing feedback on students' writing; specifically screencasting. The current research also focuses on investigating students' perception towards E-feedback; an area of research that hasn't received much attention. In addition, the present research has implications for teachers on how to implement screencasting in their writing classes and assist students in improving their writing. Curriculum designers will benefit from the study in integrating this technique of feedback into writing curriculum and consider students' needs in designing writing courses.

\subsection{Delimitations of the Research}

The present research is limited to the sample that was comprised of 63 undergraduates in EFL contexts studying a writing course. The number of the students is small so that findings may not be generalized to other contexts. The research is also limited to the mixed-methods design; pre- and post-tests and a questionnaire. Results of the questionnaire can be triangulated by qualitative instrument like interviews or students' logs to get in depth into students' perceptions. Another limitation is the writing assignments of descriptive short essays which are different from other genres. Finally, the time of the study is limited to ten weeks; therefore, a longer period is needed to reach more significant results.

\subsection{Review of Literature}

\subsubsection{Methods of Feedback}

There are various methods of giving feedback on students' essays. The most common type of feedback on students' writings is written commentary. Ellis, Loewen, and Erlam (2006) state that feedback can be categorized into three types: Feedback where teachers indicate the error, feedback where the teacher locate the error and provide correction, and feedback on the metalinguistic information about the type of the error. In direct feedback, the teacher identifies the error and corrects it directly. While in indirect feedback, the teacher locates the error and encourages students to correct themselves. This can be in the form of providing encoded feedback, general clues, or minimal marking to locate the error and its type (Lee, 2008). In indirect feedback, students are encouraged to reflect on the cognitive clues and work on linking these clues to the context of the error and correct it based on their prior knowledge. This form of feedback increases students' engagement and attention to forms and develop their problem-solving, attention, and guided-learning. When codes are used, they should be consistent and understood by students (Ferris \& Roberts, 2001; Ferris, 2003; Bitchener \& Knoch, 2009). However, some researchers opposed the value of written feedback and claimed that it produces negative results, makes students feel stressed and anxious, and increases negative attitudes towards writing. This may be due to cultural factors and perceptions towards corrective written feedback (Rami, 2012).

Furthermore, Sadler (2010) suggests that "purposeful peer assessment" be integrated in the course design. He 
also points out that peer-assessment is effective in developing students' ability of objective judgments and self-assessment when they evaluate their own work. Moreover, Vardi (2012) suggests a number of strategies to help students be "informed evaluators". Firstly, it is important to prepare students to practice peer-feedback activities and provide them with necessary information before undertaking feedback. For example, teachers should make sure that students understand the evaluation criteria and examples. Secondly, such activities should be integrated in the writing course. Thirdly, the focus of feedback should be on specific aspects of feedback. Corrective feedback should be limited to significant structures and focus on selective errors which are exhausting to students and teacher as well (Ferris \& Roberts, 2001; Ferirs, 2003; Lee, 2008).

In addition, e-feedback or computer-mediated feedback is based on providing feedback in a Word processing file or via synchronous or asynchronous conferencing. Students can access the stored feedback and print out the transcript for class discussion. Tuzi (2004) defines e-feedback as an interactive textual format transmitted on the web or via electronic medium. E-feedback is a hybrid of immediate oral as well as permanent written communication that is accessible and motivating to students (Warschauer \& Ware, 2006). There are different methods of computer-mediated feedback, such as computer conferencing, automated feedback and corpora-based feedback. Moreover, taped feedback is a form of e-feedback that saves time and provides listening practice (Jones, Georghiades, \& Gunson, 2012).

Computer-mediated feedback is effective if it occurs in a positive learning context, encourages self/peer/teacher collaboration, engages students actively in the feedback process, exchanges learning outcomes between students, and gives feedback via electronic medium (Bultrón, 2014). Likewise, Schwartz and White (2000) specify that effective online feedback should be: specific, timely, thorough, ongoing, formative, objective, individual, non-evaluative, multi-dimensional, and consistent. Online feedback aims to:

- Inform students of their performance (number and time of the tasks and the correctness of the answers)

- $\quad$ Check that students receive the feedback

- $\quad$ Provide correct answers and explanations both in case of correct or incorrect responses

- Evaluate students' responses

- Reinforce correct answers immediately

- Attract students' attention to the design and the style of the online medium

Therefore, teachers should give feedback in different ways to meet students' learning styles. Mixing of e-feedback with face-to-face conferencing can guarantee high-quality feedback and advanced revisions (Matsumura \& Hann, 2004). According to Tuzi (2004), balancing feedback should be provided on a local level (sentence, paragraph, ideas/arguments) and a macro level (audience, purpose, logic, content, organization, and development).

\subsubsection{Screencast Video Feedback (Veedback)}

The most recent technique in providing feedback especially in tertiary level is screencast video feedback (Brick \& Holmes, 2008; Ball, 2010). Screencasting is a digital recording of users' computer screen combined by voice narration to be submitted via electronic format (Word document, text file, Power Point presentation, Excel spreadsheet, website, or video). Veedback allows students to see their work, listen to recorded comments on video captures, and watch the cursor movements and pre-created annotations (AbdRahman, Salam, \& Yusof, 2014). Giving feedback via screencast video aims to improve students' writing meaningfully, increase transparency of feedback, develop revisions based on feedback given, reflect on students' writing, engage students actively in writing, meet different learning styles, and improve the quality of feedback provided by the teacher (Cunningham, 2015). Screencast feedback meets the three principles of effective feedback: global, middle-level, and micro-level comment categories (Stern \& Solomen, 2006).

Moreover, veedback is effective because (Hoyer, 2004; Kerr \& Mclaughlin, 2008; Warnock, 2008; Thompson \& Lee, 2012; Silva, 2012):

- It is easy to follow.

- It provides students with more information on their writings than written corrective feedback.

- It might improve students' listening skills.

- With the auditory and visual combination, veedback meets different learning styles as it suits dyslexic students. 
It reduces time devoted for giving written feedback and focuses teacher's attention in investing time in giving high-quality feedback.

- It increases rapport between teacher and students due to its conversational quality.

- It is suitable for distance learning environments to provide global feedback to an online class.

- $\quad$ It is available $24 / 7$ and students can easily access videos every time.

- It gives students the ability to rewind the videos and listen more than once.

- It is multimodal; this supports the idea of using more than one semiotic mode such as print, sound, and image.

Teachers who intend to use screencast video feedback should follow these steps (Jones et al., 2012):

1) Students prepare assignments in Word document or scan paper-based assignments to Adobe PDF or other electronic format.

2) Students turn in their assignments to the electronic environment or visual learning environment (VLE).

3) Teacher does the screencast video feedback by using a suitable software and start marking.

4) Teacher adds comments and annotations, highlights texts, inserts links, opens and shows other files.

5) After the session has been captured into a digital video file, the teacher uploads it to the VLE of the students' folder/ portfolio.

6) Students respond to the screencast video by watching and doing necessary modifications.

\subsection{Related Studies}

Studies that investigated the use of veedback in classroom are limited. They showed effective improvement in learning and instruction as well. Few research explored screencasting effect as a feedback tool on writing in asynchronous or blended context (Kerr \& Mclaughlin, 2008; Liou \& Peng, 2009; Silva, 2012; Thompson \& Lee, 2012). Moreover, recent research focused on students' feelings towards different feedback methods on written assignments and how this affects their performance (Birjandi \& Tamjid, 2010). Studies reported positive attitudes towards visual and auditory assessment and findings showed that students perceived e-feedback as more valid and valuable than written feedback (Denton, Madden, Roberts, \& Rowe, 2008; Crews \& Wilkinson, 2010).

Cunningham (2015) investigated 31 pre-medical students' perceptions and achievement on the feedback perceived on their writings. It also aimed at exploring the kinds of feedback provided by the instructor in traditional written and audio screencast formats. The study was divided into three strands. In the first strand, a survey was conducted to explore students' perceptions towards screencast and written feedback. In the second strand, repeated measure design was used. In the third strand, a content analysis was utilized to answer the research questions. The survey analysis revealed students' preference of the audio screencast feedback as being more individualized while perceiving the written feedback as being more specific. The survey data also revealed that a combination of both kinds of feedback is the best. The results of strand 2 data analysis showed a statistically significant increase in the students' essay scores except for assignments where traditional written feedback was given. The analysis of data from the third stand revealed that more direct and indirect feedback was given on essays when using traditional written feedback than in audio format.

Henderson and Phillips (2015) explored the attitudes of 126 undergraduate and postgraduate students towards receiving video-based assessment feedback on their assignments. The findings of the questionnaire showed that the majority of students felt positively towards veedback over text-based forms. Students perceived veedback as individualized, specific, supportive, caring and motivating, clear, detailed and unambiguous, prompting reflection, and constructive. The researcher reported some challenges faced by the students, such as anxiety about watching the videos and the difficulty of using the provided feedback. Teachers also valued veedback for being time-efficient, constructive, and motivating.

Jones, Georghiades and Gunson (2012) conducted a descriptive-exploratory study on MBA and undergraduate students to investigate the effect of screencast feedback. Data were collected from students and teacher's reflections on the use of this technique. Results showed that students enjoyed this kind of feedback and engaged more actively with the teacher's feedback and focused on assessment rather than grades.

Edwards, Dujardin and Williams (2012) explored the effect of audio-visual feedback on a distance learning course on a master's level DL module at Sheffield Hallam University. 14 students were divided into two groups 
to receive two types of feedback; written and screencast feedback. After receiving the first type of feedback, students completed a questionnaire online. After receiving the second kind of feedback, students completed the same questionnaire again. Data analysis showed that feedback is received more positively in audio-visual screencasting context. While preferences for written feedback depended on the holistic overview of a document. Researchers suggested that screencasting should be used for formative feedback and structured with spoken overview.

Similarly, Olesova (2011) investigated students' perceptions and reactions towards receiving screencast video feedback to their writings. 22 tertiary students at Universti Teknologi Malaysia took part in this study when they were required to write the first two chapters of a research report. Students were asked to work on their assignments after receiving video screencast feedback and keep a learner diary. Six students were selected randomly to participate in a focus group interview to investigate their perceptions towards video feedback. Results showed that students perceived this method of feedback positively due to factors like: multimodality effect, replay option, and narration. Difficulties reported include poor quality of sound and slow loading time.

In their study, Parton, Crain-Dorough, and Hancock (2010) explored the effect of providing 12 graduates with written feedback on their first assignment, a combination of written and video feedback on the second assignment, and only video feedback on the third. The five-minute videos were created through the use of a Flipcamera. The instructor reported the advantage of video-based feedback over written feedback in terms of giving praise for good parts and elaboration.

\subsection{Research Questions}

The research sought answers to three main questions:

1) What is the effect of screencast video feedback on enhancing students' overall writing skill?

This question can be divided into three sub-questions:

a). What is the effect of providing screencast feedback on the content of students' writing?

b). What is the effect of providing screencast feedback on the organization of students' writing?

c). What is the effect of providing screencast feedback on the structure of students' writing?

2) What is the effect of providing written feedback on the accuracy of students' writing?

3) How do students perceive screencast feedback on their writing?

\subsection{Research Hypotheses}

The present research tested the following hypotheses:

1) There would be a statistically significant difference between the experimental and control groups' mean scores on the writing posttest of overall writing skill in favor of the experimental group.

2) There would be a statistically significant difference between the experimental and control groups' mean scores on the writing posttest of content in favor of the experimental group.

3) There would be a statistically significant difference between the experimental and control groups' mean scores on the writing posttest of organization in favor of the experimental group.

4) There would be a statistically significant difference between the experimental and control groups' mean scores on the writing posttest of structure in favor of the experimental group.

5) There would be no statistically significant difference between the experimental and control groups' mean scores on the writing posttest of accuracy.

\section{Method}

\subsection{Participants}

Participants were two intact classes studying "Academic Writing 1" course in the first semester of the first year in Sadat Academy for Management Sciences in Egypt. The classes were assigned randomly into an experimental group and a control group. Of the 33 freshmen of the experimental group, 15 were males and 18 were females; whereas students of the control group were (30); 13 males and 17 females. Students in the two groups aged from 18 to 20 . Out of the 33 students of the experimental group, (10) were upper-intermediate, (12) were intermediate, (9) were elementary, and (2) were beginners-according to an English placement test carried out to students as a condition for admission to the Academy. Likewise, proficiency levels of the students of the control group on the same test were: (9) upper-intermediate, (10) intermediate, (8) elementary and (3) beginners. All students 
belonged to nearly the same cultural and economic backgrounds. The class met once a week for two hours. The students had fair computer proficiency.

\subsection{Research Design}

This is a mixed-methods design research with pre-post testing and a questionnaire. To validate the quantitative data from the questionnaire, a few open-ended questions were added to the questionnaire to expand on the findings. The pre-test of writing was administered to the experimental and control groups in $17^{\text {th }}$ of October 2015, while an equivalent form of the test was carried out in the $2^{\text {nd }}$ of January 2016. The questionnaire was administered to the experimental group at the same week of the posttest.

\subsection{Instruments}

Two instruments were created by the researcher to collect data: two equivalent writing tests and an online perception questionnaire.

\subsubsection{The Writing Tests}

The tests were created by the researcher to investigate the effect of screencast feedback on improving students' writing. The writing course in the first semester aimed at enhancing essay writing; namely descriptive essays. Therefore, students were asked to write a short descriptive essay (150-225 words) for the pretest "Describe the house in which you grew up" and another short essay in the posttest "Describe your best summer vacation". Students were allotted 20 minutes to write each essay. To determine content validity, the tests were submitted to a panel of jurors in the field of teaching EFL. The researcher improved the phrasing of the question in the second writing test based on the recommendations given by the jurors. The tests were piloted on a random sample other than that of the current study to establish the reliability of the tests. The Pearson correlation showed a high correlation coefficient between the tests $(0.91)$ which indicated that they were of the same difficulty level. Two raters scored the tests based on a rubric developed by the researcher. Each test was graded out of 16; wherein each writing component (content, organization, structure, accuracy) was assigned 4 marks. The Pearson inter-rater reliability was (0.97); which was relatively high.

\subsubsection{The Online Questionnaire}

The questionnaire aimed to explore students' perception towards the use of screencast video feedback. Questionnaire validity was established by administering it to the jurors in TEFL. Suggestions related to decreasing the number of the closed-ended items (from 20 to 18) and simplifying the language of some items were provided by the jurors and taken into consideration by the researcher. As for questionnaire reliability, it was administered to the random sample and Cronbach Alpha was found to be (0.93); which was considerably acceptable. The questionnaire was designed by the researcher with SurveyMonkey.com and the link was sent to students via Edmodo; a Learning Management System. The questionnaire consisted of 18 closed-ended items and five open-ended questions. One item out of the 18 closed-ended questions was multiple-choice whereas the other 17 items were of five-point Likert scale; ranging from (1) as strongly disagree, (2) disagree, (3) neutral, (4) agree, and (5) strongly agree. The open-ended questions sought to find explanations for the students' responses to the closed-ended statements in the questionnaire. The researcher created this part of the questionnaire to get qualitative data to triangulate the quantitative data of the first part. Unlike interviews, the open-ended questions in the questionnaire allowed all students to express their attitudes and perspectives towards veedback and enabled them to speak their mind without being shy to do it orally. The responses to the open-ended questions were transcribed and categorized respectively by five themes: the advantages of receiving veedback, disadvantages of receiving veedback, challenges encountered in receiving this kind of feedback, ways of using the given feedback, and suggestions for further feedback provision.

\subsection{Data Collection and Procedures}

The experiment lasted for 10 weeks during October and December 2015. Students in the control and experimental groups were trained on the first two sessions on accessing, interpreting, and using received digital feedback. Students in the experimental group were trained on using screencasting feedback. Participants in the two groups were instructed 8 sessions ( 2 hours each) and were given same assignments. They were asked to submit four short descriptive essays. On class time, students were trained on the format and structure of essay writing and were assigned to write the first draft at home. After writing the first drafts in a Word document, students turned in their assignments and uploaded them to Edmodo. The researcher revised the essays and wrote comments on the same documents then sent them to the students to revise and write the final drafts. Students in both groups received Word documents but students in the experimental group received additional screencast videos prepared by the researcher. Participants received two types of written feedback; direct and indirect. The 
focus of the written feedback for the experimental group was lower order concerns of writing (grammar and mechanics) while the focus for the control group was on the higher and lower order concerns of writing. The researcher discussed the comments with the students in the next session and asked them to start writing the final drafts. Students were provided with the grades once they submitted their final drafts after doing the required revisions.

The feedback provided in the screencast videos focused on microstructure revisions; adding details, adding entire paragraphs, modifying, deleting, and expanding on sentences or paragraphs. Video commentaries started with greeting students and stated the focus of feedback for each video. Then, the researcher praised the positive aspects of the paper and highlighted parts that need improvement supported with some model examples. The aim here was not to indicate all errors, but to point out error patterns and guide students in correcting them. Online resources and links were inserted to give further guidance. The researcher finished the video by giving closing remarks and asking students to write the final draft and submit it to receive the grades. Each student in the experimental group received four videos on their first drafts. Reviewing students' essays using screencast technique took a total of (160-165) minutes a week. Giving written comments took an average 3 minutes per assignment.

The screencast video feedback was recorded using Jing; a free software developed by TechSmith corporation. The tool captures the instructor's voice, editing, and highlighting comments in a document. The screencast files can be sent to students via emails or Virtual Learning Environment (VLE). Jing is utilized in this study because it allows users to mark screenshots with cues such as highlight, underlines, text, and frames. It is also accessible and affordable to teachers and students. It offers a five-minute maximum recording time; which is enough for grading short-form writing. The software generates a Uniform Resource Locator (URL) for the graded files which students can access and retrieve easily.

\section{Results}

The SPSS statistical program was used to analyze the quantitative data obtained from the tests and the closed-ended items in the questionnaire. Qualitative analysis was also used to interpret students' responses to the open-ended questions in the questionnaire. For analyzing the qualitative data, the researcher read through the responses, developed coding categories, labeled the responses with one or more coding categories on an Excel sheet, identified patterns and trends, and wrote a summary with the findings.

\subsection{Quantitative Data Analysis}

To check homogeneity of the experimental and control groups, independent samples t-test was used to compare the mean scores on the writing pretest on the overall writing skill. The significance level was $(p$. $>0.05)$; therefore, it can be inferred that students in both groups were very much similar before the experiment. Independent samples t-test was also used to compare the mean scores of the students in the control and experimental groups on the posttest. Results were analyzed in the light of the research hypotheses.

\section{Hypothesis one:}

There would be a statistically significant difference between the experimental and the control groups' mean scores on the writing posttest of overall writing skill in favor of the experimental group.

Table 1 represents the value of the statistical data on the overall writing on the posttest for the experimental and control groups.

Table 1. T-value for the posttest on overall writing skill

\begin{tabular}{llllllll}
\hline Skill & Groups & $\mathrm{N}$ & $\mathrm{M}$ & $\mathrm{SD}$ & $\mathrm{df}$ & t-value & Sig. \\
\hline Overall Writing & Experimental & 33 & 13.45 & 1.641 & 61 & 8.468 & 0.00 \\
& Control & 30 & 10.17 & 1.440 & & & \\
\hline
\end{tabular}

Table 1 shows that the mean scores of the experimental group $(M=13.45, S D=1.641)$ exceed that of the control group $(M=10.17, S D=1.440)$ on the writing posttest $(d f=61, t=8.468, p .<0.01)$. This means that hypothesis one was accepted.

Hypothesis two:

There would be a statistically significant difference between the experimental and control groups' mean scores 
on the writing posttest of content in favor of the experimental group.

Table 2 shows the value of the statistical data of content on the writing posttest for the experimental and control groups.

Table 2. T-value for the posttest on content

\begin{tabular}{llllllll}
\hline Skills & Groups & $\mathrm{N}$ & $\mathrm{M}$ & $\mathrm{SD}$ & $\mathrm{df}$ & $\mathrm{t}$-value & Sig. \\
\hline Content & Experimental & 33 & 3.36 & .549 & 61 & 5.684 & 0.00 \\
& Control & 30 & 2.43 & .728 & & & \\
& & & & & & & \\
\end{tabular}

As shown in Table 2, the mean scores for content were 3.36 and 2.43, the $S D$ were .549 and .728 for the experimental and control groups respectively; $(d f=61, t=5.684, p .<0.01)$. Consequently, this hypothesis was confirmed.

\section{Hypothesis three:}

There would be a statistically significant difference between the experimental and control groups' mean scores on the writing posttest of organization in favor of the experimental group.

Table 3 shows the value of the statistical data of organization on the writing posttest for the experimental and control groups.

Table 3. T-value for the posttest on organization

\begin{tabular}{llllllll}
\hline Skills & Groups & $\mathrm{N}$ & $\mathrm{M}$ & $\mathrm{SD}$ & $\mathrm{df}$ & t-value & Sig. \\
\hline Organization & Experimental & 33 & 3.48 & .566 & 61 & 5.997 & 0.00 \\
& Control & 30 & 2.53 & .681 & & & \\
\hline
\end{tabular}

As for the organization, the mean of the experimental group was 3.48 and $S D$ was .566 while the mean of the control group was 2.53 and $S D$ was $.681(d f=61, t=5.997, p .<0.01)$. Therefore, hypothesis three was accepted.

\section{Hypothesis four:}

There would be a statistically significant difference between the experimental and control groups' mean scores on the writing posttest of structure in favor of the experimental group.

Table 4 shows the value of the statistical data of structure on the writing posttest for the experimental and control groups respectively.

Table 4. T-value for the posttest on structure

\begin{tabular}{llllllll}
\hline Skills & Groups & $\mathrm{N}$ & $\mathrm{M}$ & $\mathrm{SD}$ & $\mathrm{df}$ & t-value & Sig. \\
\hline Structure & Experimental & 33 & 3.36 & .549 & 61 & 10.745 & 0.00 \\
& Control & 30 & 2.13 & .346 & & & \\
\hline
\end{tabular}

As shown in Table 4, the mean scores for the structure were 3.36 and 2.13, the $S D .549$ and .346 for the experimental and control groups respectively $(d f=61, t=10.745, p .<0.01)$. This shows a significant improvement in the mean scores of structure on the posttest in favor of the experimental group. Thus, hypothesis four was maintained.

Hypothesis five:

There would be no statistically significant difference between the experimental and control groups' mean scores on the writing posttest of accuracy.

To answer the second research question, the results of the students' performance on accuracy are illustrated in Table 5. 
Table 5. T-value for the posttest on accuracy

\begin{tabular}{llllllll}
\hline Skill & Tests & $\mathrm{N}$ & $\mathrm{M}$ & $\mathrm{SD}$ & $\mathrm{df}$ & t-value & Sig. \\
\hline Accuracy & Experimental & 33 & 3.21 & .545 & 61 & 1.083 & .283 \\
& Control & 30 & 3.07 & .521 & & & \\
\hline
\end{tabular}

Table 5 shows the mean scores on accuracy were 3.21 and 3.07, the $S D$ were .545 and .521 for the posttest of the experimental and control groups respectively; $(d f=61, t=1.083, p .>0.01)$. Therefore, these results verified that there was no significant difference between the experimental and control groups on students' accuracy at the 0.01 level. As a result, hypothesis five was retained.

To answer the third research question, data obtained from analyzing students' responses to the questionnaire showed that students overwhelmingly supported using screencast feedback for revising their writings. The statements were divided into five sections. The first section contained 6 items dealt with the advantages of using screencast feedback. Table 6 depicts students' responses to the benefits of receiving feedback through screencast videos.

Table 6. Descriptive statistics for advantages of screencast feedback

\begin{tabular}{lll}
\hline Items & M & SD \\
\hline 1. Receiving feedback through screencast videos helped me reshape my ideas & 4.52 & .566 \\
2. Receiving feedback through screencast videos helped me organize my writing & 4.55 & .564 \\
3.Receiving feedback through screencast videos helped me vary sentence structure & 4.45 & .506 \\
4. Receiving feedback through screencast videos is personal & 4.48 & .619 \\
5. I found screencast videos helpful because I can go back and forth & 4.88 & .331 \\
6. I found screencast videos helpful as I understand where I have lost marks & 4.58 & .561 \\
\hline
\end{tabular}

Table 6 illustrates that students viewed the benefits of screencast feedback positively. The mean scores of the students' reactions to the benefits of video feedback were relatively high. Students thought video feedback helped them reshape their ideas $(M=4.52 ; 97 \%)$, organize their essays $(M=4.55 ; 98 \%)$, and vary sentence structure $(M=4.45 ; 100 \%)$. They also perceived video feedback as personal $(M=4.48 ; 94 \%)$, helpful because of the replay feature $(M=4.88 ; 100 \%)$, and transparent $(M=4.58 ; 97 \%)$.

Responses to items 7, 8 and 9 clarified students' perceptions towards the appropriateness of sound, time, and language of the video feedback (see Table 7).

Table 7. Descriptive statistics for the appropriateness of sound, time and language of screencast feedback

\begin{tabular}{lll}
\hline Items & $\mathrm{M}$ & $\mathrm{SD}$ \\
\hline 7. The sound of the instructor in the videos was clear & 3.88 & .992 \\
8. The time of the videos was enough to understand what to revise in my & 4.55 & .506 \\
writing & & \\
9. The language used in giving the feedback was easy to understand & 4.55 & .564 \\
\hline
\end{tabular}

Students' positive responses to item 7 concerning the clarity of the sound of the videos account for $69 \%$ ( 23 students) of the total responses. No students responded negatively to items 8 and 9 regarding the adequacy of time and comprehensibility of the language.

The third section elicited students' perception towards the quality of the provided feedback. Items 10,11 , and 12 represent this section as seen in Table 8 . 
Table 8. Descriptive statistics for the quality of feedback

\begin{tabular}{lll}
\hline Items & M & SD \\
\hline 10. The instructor praised the positive aspects of my writing & 4.48 & .566 \\
11. The feedback was supported by examples/ suggestions for improvement & 4.42 & .561 \\
12. The feedback was specific and clear that I understood what exactly to revise & 4.48 & .619 \\
\hline
\end{tabular}

As shown in Table 8, responses to items 10,11 , and 12 showed that students generally perceived the quality of the provided feedback positively for being supported by praise and examples and being clear and specific $(M=$ 4.48, $M=4.42, M=4.48$ respectively).

Items 13 and 14 explored the challenges that students encountered in receiving the feedback through screencast videos as exemplified in Table 9.

Table 9. Descriptive statistics for the challenges of receiving screencast feedback

\begin{tabular}{lll}
\hline Items & $\mathrm{M}$ & $\mathrm{SD}$ \\
\hline 13. Watching screencast videos is time-consuming & 3.82 & 1.044 \\
14. I had difficulty loading the videos & 4.61 & .704 \\
\hline
\end{tabular}

24 students $(M=3.82 ; 72.8 \%$, ) agreed that they found video feedback is not time-consuming. Interestingly, 31 students $(M=4.61 ; 93.9 \%$, responded that they found no difficulty in loading the videos.

As for the final section, items (15-17) described students' attitudes towards screencast videos, as shown in Table 10.

Table 10. Descriptive statistics for attitudes towards screencast feedback

\begin{tabular}{lll}
\hline Items & M & SD \\
\hline $\begin{array}{l}\text { 15. I felt that receiving feedback through screencast videos engaged me actively in the } \\
\text { revision process }\end{array}$ & 4.45 & .564 \\
16. I have a positive attitude toward receiving feedback through screencast videos & 4.52 & .712 \\
17. I like to continue receiving video feedback in writing classes & 4.45 & .711 \\
\hline
\end{tabular}

Generally, students expressed a high degree of satisfaction with video feedback. Item 15 received a highly positive response $(M=4.45 ; 97 \%)$. Responses to item 16 regarding general attitude were fairly high, at $(M=4.52$; 94\%). $97 \%$ of the students recommended continue receiving veedback $(M=4.45)$.

Moreover, question 18 inquires about the number of times students watched the videos. Respondents have to choose an option that represents the watching frequency (one time, 2 times, 3 times, 4 times, 5 times or more). Responses to this question revealed that screencast videos were watched on average 2 times. 6 students played the video once, 16 played it twice, 5 watched it thrice, 4 watched it four times, and 2 watched it five times or more.

\subsection{Qualitative Data Analysis}

Students' responses to the open-ended questions illuminated the close-ended responses. Here is a summary of students' responses to the five open-ended questions.

\section{1) Describe what you like in screencast feedback? Why?}

The most prevalent advantages students mentioned included: clarity, attractiveness, appropriate length, helpfulness in organizing ideas and providing examples, motivating in terms of praising good performance, possibility of rewinding the videos and watching more than once, and providing chances for improving listening skills. Some students; especially visual and auditory, preferred this technique for allowing them to "see" and "hear" what was being discussed. A student noted, "I can see my assignment corrected and hear comments alive 
and not just reading them."

\section{2) Describe what you dislike in the screencast feedback? Why?}

Around $78 \%$ of the students reported no disadvantages for video feedback. $9 \%$ of the students indicated their preference for receiving paper-based feedback. A participant wrote on this regard, "I don't like uploading essays to Edmodo and getting video feedback. I found it distracting and took much time." Seven students wrote that they felt nervous before watching the first video, but they felt better because the researcher tone was friendly and she started with praising good aspects of their performance.

\section{3) Were there any difficulties? What are they?}

The common difficulty was stated in this comment by a student, "audio quality wasn't clear." Eight students commented that though the language was simple, they had to concentrate and raise the volume to hear clearly. The two students who played the video five times or more suffered from weak listening skills that hindered them from comprehending the feedback. One of them stated," I think if my listening was good, I could understand better." Nine students considered inability to download the videos to their computers for further watch a difficulty.

\section{4) How do you use the given feedback?}

Students' answers to this question confirmed their responses to items 1, 2, and 3 in the questionnaire. Students reported using feedback in improving their content and modifying supporting ideas (strongly agree $=18$, agree $=14$ ), adjusting the organization of their essays (strongly agree $=19$, agree $=13$ ), working on advancing the structure of their sentences (strongly agree $=15$, agree $=18$ ). A participant commented, "From the feedback I received on the first essay and the one I got on the last one, I think that my writing improved a lot. I write more sentences of different kinds not only simple sentences. I also worked on being more specific and to the point in writing details." In addition, participants reported that written feedback helped them to proofread their essays.

\section{5) What improvements would you recommend to improve receiving feedback on writing?}

Students suggested having the ability to download videos to their computers so that they can check even after the course. They also recommended increasing the number of examples and models of the good performance. Improving the quality of sound was also one of the suggestions provided. Increasing the length of the video and giving more details were also advised. Three students suggested providing feedback at the local or lower concerns of writing through videos rather than written comments.

\section{Discussion}

The quantitative analysis of the writing posttests answered the first research question and its sub-questions: What is the effect of screencast video feedback on enhancing students' overall writing skill? A comparison of the mean scores of the experimental group and the control group on the posttest showed statistically significant difference in favor of the experimental group at the overall writing skill as well as content, organization and structure. These results were congruent with other scholars (Liou \& Peng, 2009; Parton et al., 2010; Cunningham, 2015).

As for the second research question: What is the effect of providing written feedback on the accuracy of students' writing? Results showed no significant difference between students in the control and experimental groups in accuracy at 0.01 level; which might be attributed to the fact that both groups received written feedback on their writings. This result echoes the findings of previous studies investigated the effectiveness of using written feedback on students' writings in improving accuracy (Ferris \& Roberts, 2001; Bitchner \& Knock, 2008). When asked about the way by which they made use of the given feedback, students reported benefiting from written comments in proofreading their essays.

The analysis of the data obtained from the online questionnaire, both the closed-ended and the open-ended questions, answered the third question: How do students perceive screencast feedback on their writing? Data analyses revealed that students were more interested in receiving feedback through screencasting; a finding that was in line with other researchers (Birjandi \& Tamjid, 2010; Olesova, 2011; Edwards et al., 2012; Henderson \& Philips, 2015).

These results might be attributed to the advantages of veedback as indicated by the responses to the questionnaire. (94\%) of the students in this study reported having positive attitude towards veedback and (97\%) recommended continuing receiving veedback on their writing. However, students highlighted some disadvantages or difficulties in receiving feedback through this technique. The following are the advantages and disadvantages of veedback as reported by the participants in this research. 


\section{Advantages of screencasting}

These advantages can be categorized into four main features: clarity and comprehensibility, constructivism, multimodality and availability, and individualism.

\section{- Clear and comprehensive}

Screencast feedback was perceived as being clear, specific, and detailed. About (94\%) of the students agreed that: The feedback was specific and clear that I understood what exactly to revise. The multimodality of videos enabled students to clearly spot areas to revise in their writing; as indicated by a student, "It was helpful in correcting and revising assignments as I played the videos more than once to know what to revise." Many factors contributed to this result. First, the comprehensibility and clarity of the language used by the researcher as shown in the students' reply to the ninth item in the questionnaire: The language used in giving the feedback was easy to understand (strongly agree $=19$ agree $=13$ ). Second, the suitability of the video duration; video commentaries was of five minutes length (600-750 words). All respondents agreed that: The time of the feedback video was enough to understand what to revise in my writing (strongly agree $=18$, agree $=15$ ). Third, veedback was detailed and directed to specific writing features like content, organization, and structure. A student commented, "The video was more elaborative than written feedback" and another student wrote, "I think videos were more detailed than written feedback and also specific."

\section{- Constructive feedback}

Students' responses to the questionnaire indicated that feedback was constructive in terms of giving models to reflect on and use to improve their future writing. Responses to item eleven in the questionnaire: The feedback was supported by examples/ suggestions for improvement (strongly agree $=15$, agree $=17$ ) supported Hattie and Timperley (2007), who argued that feed forward is pivotal when it inspires students to think about the process they use to produce work. In addition, students considered feedback helpful in providing them ways to improve and not just highlighting errors. (97\%) of the students considered receiving praise on their writings encouraging and supportive as demonstrated in their responses to this item: The instructor praised the positive aspects of my writing. This helped students to reinforce points of strengths and improve areas of weaknesses in their writings. The following quotes by students corroborate that veedback is feed forward:

"Feedback guided me to correct mistakes and not only pointing mistakes".

"It helped me know what specific things to revise. I also like the friendly way of giving comments"

Like students in Davis and McGrail's study (2009), students in the current research made revisions at the higher order concerns rather than surface or lower order revisions. Quantitative analysis of the posttest showed that students in the experimental group outperformed their counterparts in the control group in content, organization, and structure of writing. Similarly, this result is consistent with students' responses to items 1, 2, and 3 in the questionnaire. In responding to the fourth open-ended question: How do you use the given feedback? , students highlighted making improvements in these areas when revising their essays. This might be attributed to the fact that these features were the main focus of the videos. (97\%) of the students reported transparency of the given feedback: I found screencast videos helpful as I understand where I have lost marks.

\section{- Multimodal and available}

The multimodality of the video feedback allowed students to trace on-screen movement and follow the cursor which made the feedback easy to follow and more directed. A student commented, "It was easy to follow the parts the doctor (researcher) pointed to by the mouse. I paused and made immediate revisions." Henderson and Phillips (2015) pinpointed that seeing the instructor's face and listening to his voice made students felt the feedback to be "real", "honest" and "authentic".

As indicated by Warnock (2008), students saved time of meeting face-to-face with the researcher. While the researcher's comments in face-to-face meetings can't be repeated, students could replay the videos more than once. All students reported the advantage of being able to play the videos back and forth several times in responding to this item: I found screencast videos helpful because I can go back and forth (strongly agree $=29$, agree $=4$ ). This finding is consistent with Parton et al. (2010), who found that participants in their study felt that the availability of the videos beyond class hours (24/7) enabled them to watch the videos anytime and on their own pace. Students reported watching the videos, taking notes, and correcting the errors at the same time. Consequently, (97\%) of the students reported being engaged and involved in the revising process as indicated by their responses to this item: I felt that receiving feedback through screencast videos engaged me actively in the revision process. This finding supported Seliem and Ahmed (2009) who argued that e-feedback increased students' engagement and the time they spent in writing. 


\section{- $\quad$ Personal and Individualized}

The nature of veedback helped students to think of feedback as a conversation. The researcher's voice conveys positive encouragement; a feeling which overcame students' anxiety and built self-efficacy. A student noted, "I was nervous and worried as it is the first time to receive video feedback, but I became better after few minutes of listening to what good in my essay." By reducing anxiety and face-threatening critique, students were able to perceive feedback more positively and strengthen teacher-student relations. This advantage was highlighted by Edwards et al. (2012) who found that students in their study valued screencasting over written corrective feedback.

Moreover, (94\%) of the students in the present study reported the personal and individualized nature of veedback comments that made them feel valued as students and pay more attention to them; which matched the students' responses in Thompson and Lee (2012)'s study. A student commented, "The doctor (researcher) talked to me personally and I understood where I made errors." Similarly, Parton et al. (2010) perceived the primary benefit of the veedback was creating a rapport between instructors and students. This is in line with Crews and Wilkinson (2010)'s conclusion that this technique improved students' writing by helping them to identify the types of errors and create a friendly rapport with the teacher. Therefore, students were actively engaged in the revision process.

In addition to these advantages, some students reported that video feedback might improve their listening; which agrees with Thompson and Lee (2012)'s finding that veedback can develop active listening behavior. Low-proficiency listeners can be provided by written text to accompany the oral comments to help them make use of the given feedback. A student wrote, "I prefer hearing the doctor (researcher) voice rather reading her comments. For me it is a listening exercise."

Moreover, classroom discussions helped students to understand some commentaries on their essays by discussing them with peers and the researcher. A student noted, "When I had problem in understanding some comments, I discuss them with doctor and friends in sessions."

\section{Disadvantages of screencasting}

Technical problems, anxiety, and preference for written feedback constituted the major disadvantages of screencasting.

Similar to Olesova (2011)'s study, (27\%) of the students in the present research reported difficulty in downloading the videos as the free version of Jing creates SWF files that require a Flash player to open and often requires students to specify which program to open the file with. Alternative software programs provide users with the options of saving video files in the MP4 format to be easily opened or played on other media devices (such as iPods). However, MP4 files are larger than SWF files, and are more difficult to download or upload. In addition, (3) students who had heavy internet speed at home reported waiting while videos were loading. They paused the video to allow it to finish loading. Furthermore, (69\%) of the students pinpointed that the sound of the videos was not clear enough.

Students' unfamiliarity with screencasting made them anxious about the provided feedback. In answering the open-ended question: Describe what you dislike in the screencast feedback? Why? (21\%) of the students reported being anxious about the content of the feedback. A student stated, "As a new experience I worried about my grade and what I will hear from doctor. I liked the way she gives feedback and I waited for other videos." This finding is consistent with Henderson and Phillips (2015)'s study in which participants reported initial anxiety about playing screencast videos. Likewise, Matsumura and Hann (2004) found that computer anxiety can hinder the use of e-feedback.

About (9\%) of the students compared veedback to written feedback and believed that written commentaries can easily be accessed and traced in minutes. They preferred written feedback and believed that it is more global and nonlinear. Same students perceived video feedback as time-consuming and believed that reviewing written feedback takes less time. 50\% of the students in Edeiken-Cooperman and Berenato (2014)'s study preferred handwritten feedback to electronic feedback as the former allowed them to create a more personal rapport with their lecturers. They also showed more appreciation to the lecturers' time when giving handwritten feedback.

Responses to question 18 inquiring about the frequencies of listening to the videos revealed that screencast videos were watched on average 2 times. Two out the eleven students who reported watching the videos more than twice stated that weak listening competencies prevented them from comprehending the given feedback quickly. 


\section{Conclusion and Recommendations}

This research investigated the efficacy of incorporating screencast feedback in an EFL writing course on university students' writing skill and perception. Screencast feedback proved effective in improving students' essay writing skills. Students in this study demonstrated a positive attitude towards veedback and perceived it to be succinct, unambiguous, multimodal, personal, feed forward, and motivating. They also reported some disadvantages like heavy downloading of the videos, nervousness, and linearity. In conclusion, this research explores areas of strengths and weaknesses of using screencasting in giving formative assessment on short essays; as perceived by a sample of EFL students in Egyptian context.

Future studies are needed to explore the use of screencasting on developing other language skills. Further research needs to evaluate whether the potential challenges of using veedback outweigh the benefits for learning. In addition, students' preference for modality feedback (e.g. audio, video, text) and ways to provide feedback to different learning styles should be explored. It is also highly recommended to investigate the effect of using veedback on students' self-efficacy at different learning contexts. More research is also required to explore the patterns and behaviors that students follow in revising their assignments using video feedback. Further research needs to account for teachers' perception and attitude when experiencing this technique.

In the light of the research findings, EFL teachers are recommended to involve students in assessment by encouraging them to use "track change" function in Word processing to insert questions or comments to reflect on their thoughts and difficulties. Furthermore, students should use rubrics and assess their peers' writings and discuss their own marking with teachers. Students can be also encouraged to create their own videos commenting on their own or peers' essays. Two-stage assignment is also beneficial as it allows students to redraft their assignments after receiving the feedback from the teacher or peers and then reflect on how they made use of the feedback and improve their performance in the future. Teachers can use video feedback for summative feedback (for giving grades) in peer-feedback, student-to-instructor feedback exchanges in recorded lecturers of flipped classroom contexts. It is also recommended to provide students with models of good performance to which they compare their performance. It is advisable to try other capture programs like Camtasia to help students download videos to their computers. Finally, students might feel frustrated by this new method of feedback if they don't receive appropriate training on new strategies to engage with this kind of feedback. Students should be trained on how to interpret and make use of the digital feedback.

\section{References}

AbdRahman, S., Salam, A., \& Yusof, M. (2014). Screencast Feedback Practice on Students' Writing. Paper presented at Asia-Pacific Social Science Conference 2014, Seoul, Korea, APSSC. Retrieved from https://www.researchgate.net/publication/289396637_Screencast_Feedback_Practice_on_Students'_Writing

Ball, E. (2010). Annotation an effective device for student feedback: A critical review ofthe literature. Nurse education in practice, 10(3), 138-143. http://dx.doi.org/10.1016/j.nepr.2009.05.003

Birjandi, P., \& Tamjid, N. (2010). The role of self-assessment in promoting Iranian EFL learners' motivation. English Language Teaching, 3(3), 211-220. http://dx.doi.org/10.5539/elt.v3n3p211

Bitchener, J., \& Knoch, U. (2009). The relative effectiveness of different types of directwritten corrective feedback. System, 37(2), 322-329. http://dx.doi.org/10.1016/j.system.2008.12.006

Brick, B. \& Holmes, J. (2008). Using Screen Capture Software for Student Feedback. In D. Klinshuk, G. Sampson, J. M. Spector, P. Isaias, \& D. Ifenthaler (Eds.), Cognition and Exploratory Leaning in Digital Age: Proceedings of the IADIS CELDA 2008 Conference IADIS CELDA 2008 (pp. 339-342). IADIS. Retrieved from https://curve.coventry.ac.uk/open/file/.../brickiadis.pdf

Bultrón, A. (2014). The use of teacher-written feedback and computer-media ted feedback to enhance ePuerto Rican English as a Second Language (ESL) high school students' essay writing (Doctoral dissertation). Available from ProQuest Dissertation \& Theses: Full Text (NR3631241).

Crews, T., \& Wilkinson, K. (2010). Students' perceived preference for visual and auditory assessment with e-handwritten feedback. Business Communication Quarterly, 73(4), 399-412. http://dx.doi.org/10.1177/1080569910385566

Cunningham, M. (2015). Using audio screencast for feedback on short written essays (Doctoral dissertation). Available from ProQuest Dissertation \& Theses: Full Text (NR3733157).

Davis, A., \& McGrail, E. (2009). Proof-revising' with Podcasting: Keeping readers in mind as students listen to and rethink their writing. Reading Teacher, 62(6), 522-529. http://dx.doi.org/10.1598/RT.62.6.6 
Denton, P., Madden, J., Roberts, M., \& Rowe, P. (2008). Students' response to traditional and computer-assisted formative feedback: A comparative case study. British Journal of Educational Technology, 39(3), 486-500. $\mathrm{http}: / / \mathrm{dx}$.doi.org/10.1111/j.1467-8535.2007.00745.x

Edeiken-Cooperman, N., \& Berenato, C. (2014). Students' perceptions of electronic feedback as an alternative to handwritten feedback: One university's inquiry. Journal of Education and Learning, 3(1), 79-85. http://dx.doi.org/10.5539/jel.v3n1p79

Edwards, K., Dujardin, A., \& Williams, N. (2012). Screencast feedback for essays on a distance learning MA in Professional Communication: An action research project. Journal of Academic Writing, 2(1), 95-126. http://dx.doi.org/10.18552/joaw.v2i1.62

Ellis, R., Loewen, S., \& Erlam, R. (2006). Implicit and explicit corrective feedback and the acquisition of L2

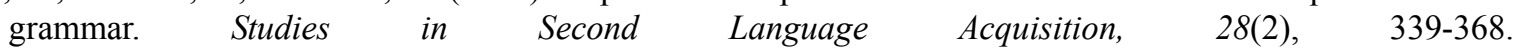
http://dx.doi.org/10.1017/S0272263106060141

Ferris, D. (2003). Response to student writing. Mahwah, NJ: Lawrence Erlbaum.

Ferris, D., \& Roberts, B. (2001). Error feedback in L2 writing classes: How explicit does it need to be? Journal of Second Language Writing, 10(3), 161-184. http://dx.doi.org/10.1016/S1060-3743(01)00039-X

Gibbs, G., \& Simpson, C. (2004). Conditions under which assessment supports students' learning. Learning and Teaching in Higher Education, 1(1), 3-31.

Hattie, J. A., \& Timperley, H. (2007). The power of feedback. Review of Educational Research, 77(1), 81-112. http://dx.doi.org/10.3102/003465430298487

Henderson, M., \& Phillips, M. (2015). Video-based feedback on student assessment: scarily personal. Australasian Journal of Educational Technology, 31(1), 51-66. http://dx.doi.org/10.14742/ajet.1878

Hoyer, J. (2004). Enhancing the "Show and Tell" aspects of class engagement using Camtasia, a low-cost video screen capture replay technology. Paper presented at the Ninth Annual Instructional Technology Conference: Transforming the Learning Environment, University of Colorado, Boulder, Colorado. Retrieved fromhttp://www.mtsu.edu/ itconf/proceed04/hoyer.pdf

Hyland, K., \& Hyland, F. (Eds.). (2006). Feedback in second language writing: Contexts and issues. New York, NY: Cambridge University Press. http://dx.doi.org/10.1017/CBO9781139524742

Jones, N., Georghiades, P., \& Gunson, J. (2012). Student feedback via screen capture digital video: Stimulating student's modified action. High Education, 64(5), 593-607. http://dx.doi.org/10.1007/s10734-012-9514-7

Kerr, W., \& Mclaughlin, P. (2008). The benefit of screen recorded summaries in feedback for work submitted electronically. In F. Khandia (Ed.), 12th CAA International Computer Assisted Assessment Conference: Proceedings of the Conference on 8th and 9th July 2008 (pp. 153-168). Loughborough: Loughborough University.

Lee, I. (2008). Understanding teachers' written feedback practices in secondary classrooms. Journal of Second Language Writing, 17(2), 69-85. http://dx.doi.org/10.1016/j.jslw.2007.10.001

Liou, H. C., \& Peng, Z. Y. (2009). Training effects on computer-mediated peer review. System, 37(3), 514-525. http://dx.doi.org/10.1016/j.system.2009.01.005

Liu, J., \& Sadler, R. (2003). The effect and affect of peer review in electronic versus traditional modes on L2 writing. Journal of English for Academic Purposes, 2, 193-227. http://dx.doi.org/10.1016/S1475-1585(03)00025-0

Matsumura, A., \& Hann, G. (2004). Computer anxiety and students' preferred feedback methods in EFL writing. The Modern Language Journal, 88(3), 403-415. http://dx.doi.org/10.1111/j.0026-7902.2004.00237.x

Nicol, D. J., \& Macfarlane-Dick, D. (2006). Formative assessment and self-regulated learning: A model and seven principles of good feedback practice. Studies in Higher Education, 31(2), 199-216. http://dx.doi.org/10.1080/03075070600572090

Olesova, L. (2011). An examination of the effectiveness of embedded audio feedback for English as a Foreign Language students in asynchronous online discussions (Doctoral dissertation). Available from ProQuest Dissertation \& Theses: Full Text (NR3506374).

Parton, B. S., Crain-Dorough, M., \& Hancock, R. (2010). Using flip camcorders to create video feedback: Is it realistic for professors and beneficial to students? International Journal of Instructional Technology \& 
Distance Learning, 7(1), 15-23.

Price, M., Handley, K., Millar, J., \& O’Donovan, B. (2010). Feedback: All that effort, but what is the effect? Assessment \& Evaluation in Higher Education, 35(3), 277-289. http://dx.doi.org/10.1080/02602930903541007

Rami, F. M. (2012). Feedback on the Feedback: Sociocultural Interpretation of Saudi ESL Learners' Opinions about Writing Feedback. English Language Teaching, 5(3), 3-15. http://dx.doi.org/10.5539/elt.v5n3p3

Sadler, D. (2010). Beyond feedback: Developing student capability in complex appraisal. Assessment \& Evaluation in Higher Education, 35(5), 535-550. http://dx.doi.org/10.1080/02602930903541015

Schwartz, F., \& White, K. (2000). Making sense of it all: giving and getting on-linecourse feedback. In White, K. W., \& Weight, B. H. (Eds.), The on-line teaching guide (pp. 167-182). Boston, London: Allyn \& Bacon, 2000.

Seliem, S., \& Ahmed, S. (2009). Missing: Electronic feedback in Egyptian EFL essay writing classes. Paper Presented at CDELT Conference, Faculty of Education, Ain Shams University, Egypt. Retrieved from http://files.eric.ed.gov/fulltext/ED505841.pdf

Silva, M. (2012). Camtasia in the classroom: student attitudes and preferences for video commentary or Microsoft Word comments during the revision process. Computers and Composition, 29(1), 1-22. http://dx.doi.org/10.1016/j.compcom.2011.12.001

Stern, L., \& Solomon, A. (2006). Effective faculty feedback: The road less traveled. Assessing Writing, 11(1), 22-41. http://dx.doi.org/10.1016/j.asw.2005.12.001

Thompson, R., \& Lee, M. (2012). Talking with Students through Screencasting: Experimentations with Video Feedback to Improve Student Learning. Journal of Interactive Technology and Pedagogy, 1, 1-16.

Tuzi, F. (2004). The impact of e-feedback on the revisions of L2 writers in an academic writing course. Computers and Composition, 21(2), 217-235. http://dx.doi.org/10.1016/j.compcom.2004.02.003

Vardi, I. (2012). Effective feedback for student learning in higher education: HERDSA.

Warnock, S. (2008). Responding to student writing with audio-visual feedback. In T. Carter, \& M. A. Clayton (Eds.), Writing and the iGeneration: Composition in the computer-mediated classroom (pp. 201-227). Southlake, TX: Fountainhead Press.

Warschauer, M., \& Ware, P. (2006). Automated writing evaluation: defining the classroom research agenda. Language Teaching Research, 10(2), 157-180. http://dx.doi.org/10.1191/13621688061r190oa

Zhang, Z., \& Kenny, R. (2010). Learning in an online distance education course: Experiences of three international students. The International Review of Research in Open and Distance Learning, 11(1).

\section{Copyrights}

Copyright for this article is retained by the author(s), with first publication rights granted to the journal.

This is an open-access article distributed under the terms and conditions of the Creative Commons Attribution license (http://creativecommons.org/licenses/by/4.0/). 